Elsevier Sequoia S.A., Lausanne - Printed in The Netherlands

THE POTENTIAL AND CONCENTRATION DEPENDENCY OF THE ADSORPTION OF LEAD(II) AT THE MERCURY-1 $M$ KCl SOLUTION INTERFACE

M. SLUYTERS-REHBACH, J. S. M. C. BREUKEL, K. A. GIJSBERTSEN, C. A. WIJNHORST and J. H. SLUYTERS

Laboratory of Analytical Chemistry, State University Utrecht (The Netherlands)

(Received 27th October 1971; in revised form 24th December 1971)

\title{
INTR ODUCTION
}

It is well known in double-layer electrochemistry that almost all common anions can be specifically adsorbed at mercury from aqueous solutions. A species is said to be specifically adsorbed if its surface excess is not caused simply by coulombic interaction between the charges of species and electrode. Regarding the double-layer structure, the specifically adsorbed amount is thought to be situated in the so-called inner layer, i.e. between the plane of closest approach of hydrated ions and the electrode surface. So far, specific adsorption of cations has, with the exception of caesium ${ }^{1}$ and thallium $^{2}$, not been indicated in thermodynamic double-layer analysis.

After the evolution of kinetic techniques such as impedance analysis ${ }^{3}$ and chronocoulometry ${ }^{4,5}$, it appeared that many other cations must be specifically adsorbed, even from solutions containing millimolar concentrations of these cations. Probably, the conditions for it to occur are rather general: the cation must be present in the solution as a complex, while the complexing ligand (anion) itself is specifically adsorbed. In other words, cation adsorption seems to be induced by the already existing anion adsorption. It should be noted that this rule cannot be reversed : not in all systems where a cation forms complexes with specifically surface active anions, is the cation adsorbed.

A typical example is the adsorption of lead ions from chloride solutions, which has been studied by various authors including Timmer $e t$ al. ${ }^{6}$ by means of impedance analysis in the potential region of the faradaic reaction, Caselli and Papoff ${ }^{7}$ with chronoamperometry and Barclay and Anson ${ }^{8}$ with chronocoulometry at potentials anodic to the faradaic region. From Timmer's work it appeared that, with the concentration used for these experiments $(<1 \mathrm{mM})$, there is no detectable influence on the value of the double-layer capacity at potentials anodic to the faradaic reaction. This is opposite to the behaviour of, for example, indium in thiocyanate solution ${ }^{9}$, which shows a slight decrease in capacity in the region anodic to the onset of the reduction wave.

To investigate this further we made capacity measurements at higher lead concentrations and found, surprisingly, a dramatic effect which, as far as we know, has not been reported earlier. The results of this study will be dealt with and discussed in this paper. This study also included some chronocoulometric experiments. 
It had been found previously ${ }^{10}$ that d.c. polarograms of $\mathrm{Hg}(\mathrm{II})$ and $\mathrm{Bi}(\mathrm{III})$ in bromide and iodide solutions were distorted by the presence of lead ions. Correlation with specific lead adsorption seemed obvious. In this paper it will be shown that in chloride solution a similar distortion occurs and that the phenomenon is directly related to the anomalous behaviour of the double-layer.

\section{EXPERIMENTA.L}

Solutions were made of p.a. chemicals, $\mathrm{KCl}, \mathrm{HCl}, \mathrm{Pb}\left(\mathrm{NO}_{3}\right)_{2}$ and $\mathrm{BiONO}_{3}$ in doubly distilled water. The solubility of $\mathrm{Pb}$ (II) in $1 M$ chloride solution is somewhat more than $4 \mathrm{mmol}^{-1}$.

Double-layer capacities were measured as a function of potential in the potential region anodic to the onset of the $\mathrm{Pb}$ (II) reduction wave, by means of the impedance bridge described earlier ${ }^{11}$. The indicator electrode was either a dropping mercury electrode (DME) or a stationary drop electrode suspended on a thin platinum wire (HMDE). The d.c. potential was measured against a saturated calomel electrode (SCE).

The chronocoulometric experiments were performed with the P.A.R. electrochemistry system, model 170 using a HMDE.

For the polarographic experiments a Metrohm Polarecord was used.

All measurements were performed at $25^{\circ} \mathrm{C}$.

\section{RESULTS AND DISCUSSION}

\section{(i) Capacity measurements at the DME}

The most significant feature of the capacity-potential curves in Fig. 1 is the sudden drop in capacity occurring at a specific potential for each $\mathrm{Pb}$ (II) concentration above $1 \mathrm{~m} M^{\star}$. The shapes of the curves strongly resemble those frequently observed in the presence of capillary-active organic species. However, there are differences. Firstly, the minimum of the curves is not situated at or near the potential of zero charge. Secondly, the peaks, though found at concentration-dependent potentials, do not have concentration-dependent heights. Also, only a slight frequency dispersion (less than $1 \mu \mathrm{F} \mathrm{cm}^{-2}$ ) is observed at the peak potentials, contrary to the rather large frequency-dependence usually found at the desorption peaks of organic substances. Besides, it is not logical to consider the peaks as "desorption peaks" because it is already known that $\mathrm{Pb}(\mathrm{II})$ is still adsorbed at the more negative potentials, even in the region of the faradaic reaction, which is left out of consideration in Fig. 1 (note that negative to the peak $C_{\mathrm{d}}$ is different from $C_{\mathrm{d}}$ at $c_{\mathrm{Pb}}=0$ ).

Recently Barclay and Anson ${ }^{8}$ studied the adsorption of lead from a $0.7 \mathrm{mM}$ solution in $1 \mathrm{M} \mathrm{KCl}$ by means of chronocoulometry. They observed an increase in the adsorption going to more positive potentials. This was interpreted by assuming that the adsorption is induced by the chloride ions already adsorbed in the inner layer. They further had argued that the adsorbed species is the negatively charged $\mathrm{PbCl}_{4}^{2-}$ complex, as was also postulated by Caselli and Papoff ${ }^{7}$.

* A similar decrease in capacity has been found by Lauer and Osteryoung for the system $1 \mathrm{~m} M \mathrm{Zn}(\mathrm{II})$ in $\mathrm{NCS}^{-}$solution ${ }^{12}$. 
In view of the work of Barclay and Anson we could interpret our capacitypotential curves in the following way. The increase in capacity with $\mathrm{Pb}$ concentration observed at potentials negative to the "drop-down potential" supports the idea that an ionic species is adsorbed ( $c f$. the increase in capacity when halide anions are adsorbed). If this adsorption increases going to positive potentials, it is conceivable that at a certain potential a saturation coverage will be reached. Beyond that potential the adsorbed species may form a monolayer which causes the drop in capacity. At larger concentrations the amount of adsorption will be relatively larger and the saturation coverage will be reached at a more negative potential.

The question arises as to whether the monolayer still consists of ionic species. An argument against this idea is the consideration that repulsion forces will prevent the formation of a close-packed layer. Moreover, there is the experimental fact that at $1.5 \mathrm{mM}$ and $2 \mathrm{mM} \mathrm{Pb}$ (II) concentrations the capacity rises again at a potential close to $0 \mathrm{~V} v \mathrm{~s}$. SCE. If this means that the monolayer is destroyed by desorption it is not logical to suppose that a negatively charged ion is desorbed at a positive potential. If the adsorbed species is neutral, however, the rise in capacity could correspond to a desorption due to the replacement of the neutral species by water molecules, similar to the behaviour of neutral organic species.

\section{(ii) Chronocoulometric measurements}

In order to check the validity of the foregoing reasoning it appeared useful to determine the amount of $\mathrm{Pb}(\mathrm{II})$ adsorbed as a function of potential at concentrations of $1 \mathrm{mM}$ and above. For this purpose we applied double-potential step chronocoulo-
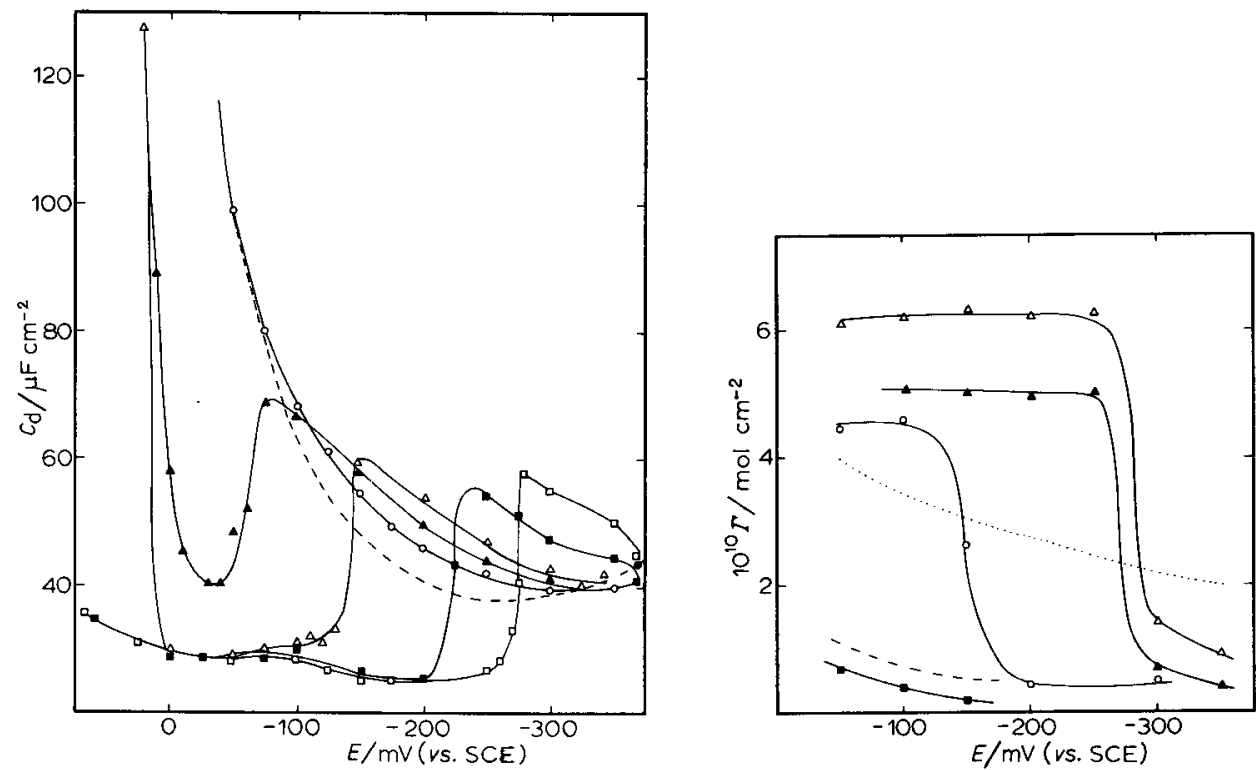

Fig. 1. Differential double-layer capacities of the DME in $1 \mathrm{M} \mathrm{KCl}$ solns. containing $\mathrm{Pb}(\mathrm{II})$ at concns. :(---) $0,(\mathrm{O}) 1,(\boldsymbol{\Delta}) 1.5,(\triangle) 2,(\mathbb{C}) 3,(\square) 4 \mathrm{mM}$. Measuring frequency $1000 \mathrm{~Hz}$.

Fig. 2. Adsorbed amounts of $\mathrm{Pb}(\mathrm{II})$ as function of potential, determined by double-potential step chronocoulometry. Concns.: $(\triangle) 2,(\Delta) 1.5,(\bigcirc) 1,(\mathbf{D}) 0.7 \mathrm{mM}$. (--) Results of Barclay and Anson for $0.7 \mathrm{mM}$, $(\cdots) \Gamma_{\mathrm{Cl}^{-}}$in $1 \mathrm{M} \mathrm{KCl}$ soln.

J. Electroanal. Chem.. 38 (1972) 
metry, as described by Anson and Barclay ${ }^{5}$. The potential was stepped from the initial potential, adjusted against the SCE, to a potential in the limiting current range of the $\mathrm{Pb}(\mathrm{II})$-reduction wave, and after a certain time backwards to the initial potential. As the theory predicts the charge $Q$, passing the cell, was a linear function of the square root of time $t$ for $0<t<\tau$ and of $t-\tau$ for $t>\tau$. The difference of the intercepts of both lines was set equal to $n F \Gamma_{\mathrm{Pb}(\mathrm{II})}$. It should be noted that the procedure followed gives rather inaccurate results for low values of $\Gamma$, because the determination involves subtraction of two large quantities. This may explain the fact that results for $0.7 \mathrm{mM}$ $\mathrm{Pb}$ (II) differed somewhat from those of Barclay and Anson's ${ }^{8}$ results (see Fig. 2) although the order of magnitude is the same. Despite the possibly poor accuracy of our results at low coverages, the results for higher $\mathrm{Pb}(\mathrm{II})$ concentrations are qualitatively noteworthy. Instead of increasing gradually to a saturation value at positive potentials, a sudden increase is found for $1 \mathrm{mM} \mathrm{Pb(II)}$ at $-150 \mathrm{mV}$ and for 1.5 and $2 \mathrm{~m} M$ at $-280 \mathrm{mV} v \mathrm{~s}$. SCE. At potentials positive to these inflection points the coverage is independent of potential. Its level, however, increases with concentration and is, therefore, not really a saturation level.

It is interesting to note that $\Gamma_{\mathrm{Pb}(\mathrm{II})}$ in the region positive to the inflection potential is much larger than the amount of chloride ions adsorbed from the supporting electrolyte in the absence of lead (see Fig. 2). This indicates that the mechanism proposed by Barclay and Anson, i.e. the reaction of one adsorbed $\mathrm{Cl}^{-}$ion with $\mathrm{PbCl}_{3}^{-}$to adsorbed $\mathrm{PbCl}_{4}^{2-}$, is no longer valid. It seems more realistic to assume that $\mathrm{Pb}^{2+}$ and $\mathrm{Cl}^{-}$ions enhance the adsorption of each other mutually, leading to the formation of a dense layer of $\mathrm{PbCl}_{y}^{2-y}$ at a certain potential.

(iii) Capacity measurements at the HMDE

When Figs. 1 and 2 are compared, it appears that for a given concentration the inflection in the $C_{\mathrm{d}} v s . E$ and the $\Gamma v s . E$ curves occur at different potentials. Moreover, at $1 \mathrm{mM} \mathrm{Pb}(\mathrm{II})$ the capacity does not show the minimum, whereas the adsorbed amount still exhibits a sudden increase. The experimental circumstances of the two series of experiments are different in that the capacity measurements were performed at the DME (drop time $3 \mathrm{~s}$ ), whereas the chronocoulometric experiments were performed at a HMDE, equilibrated with the solution in $c a .30 \mathrm{~s}$. If this difference is responsible for the inconsistency, this can be checked by capacity measurements at the HMDE.

While performing such measurements, we found that the capacity of a fresh mercury drop was time-dependent, reaching a final value after $c a .30 \mathrm{~s}$ (in the "jump region" $c a .60 \mathrm{~s}$ ). The inflection potential at $1 \mathrm{mM} \mathrm{Pb}$ (II) concentration, $-150 \mathrm{mV}$ $v s$. SCE, corresponds closely to the inflection of the $\Gamma$ vs. $E$ curve. The plot for 1.5 $\mathrm{m} M \mathrm{~Pb}(\mathrm{II})$ is similar to that of $1 \mathrm{~m} M \mathrm{~Pb}(\mathrm{II})$; however, the inflection potential is different from that in Fig. 2. For $2 \mathrm{~m} M$ concentration a remarkable "double jump' is found at -240 and $-275 \mathrm{mV}$ respectively. $\mathrm{Up}$ to $2 \mathrm{mM}$ the capacities negative to the jump are larger than in $\mathrm{KCl}$ alone. At 3 and $4 \mathrm{mM}$ the capacity curves, which are coincident, show a jump at $-250 \mathrm{mV}$, and are almost horizontal at the negative side. The total behaviour indicates that at these concentrations the second jump occurs at more negative potentials. We could not verify this because at $-350 \mathrm{mV} \mathrm{Pb}$ (II) reduction starts. Finally, the anodic rise, found for 1.5 and $2 \mathrm{mM}$ at the DME, is lacking at the HMDE.

J. Electroanal. Chem., 38 (1972) 
The different results obtained at the DME and the HMDE require an explanation. As the only significant difference is the time scale of the experiment, it might be inferred that diffusion of lead ions, which are present in small concentration, determines the rate of adsorption. Koryta has derived an expression for adsorption at the DME, reading

with

$$
\Gamma / \Gamma_{\mathrm{m}}=(t / \vartheta)^{\frac{1}{2}}
$$

$$
\vartheta=1.85 \times 10^{6}\left(\Gamma_{\mathrm{m}} / c \sqrt{ } D\right)^{2}
$$

in which $\Gamma_{\mathrm{m}}$ is the adsorbed amount corresponding to the equilibrium situation. The other symbols have their usual meaning. This simple set of equations, however, cannot explain the fact that both at the DME and the HMDE saturation seems to be established, but within different potential ranges.

With regard to our experimental results and to what is already known about adsorption of $\mathrm{Pb}$ (II) from chloride solution ${ }^{6-8}$, we are inclined to accept the following tentative model. At a fresh mercury drop, chloride ions will be adsorbed rapidly because their concentration is high. The adsorbed chloride ions will attract $\mathrm{Pb}$ (II) to the inner layer, because of the tendency to complex formation. The lead species, in its turn enhances $\mathrm{Cl}^{-}$adsorption. These two processes are time-dependent because $\mathrm{Pb}$ (II) has to diffuse towards the interface. After a certain time an equilibrium will be established between adsorbed $\mathrm{PbCl}_{y}^{2-y}$ and the lead species in the solution. The adsorbed amount, $\Gamma_{\mathrm{PbCl}_{y}}$, at potentials negative to the jump in Figs. 1,2 or 3, increases with potential because adsorption of $\mathrm{Cl}^{-}$, which initiated the whole process, increases with potential.

At low coverages the $\mathrm{PbCl}_{y}^{2-y}$ species is probably a charged species, since at low concentrations and at negative potentials the double-layer capacity is increased by the presence of $\mathrm{Pb}$ (II). This is in accordance with the views of Barclay and Anson ${ }^{8}$, who found arguments which support the idea that $\mathrm{PbCl}_{4}^{2-}$ is the adsorbed species.
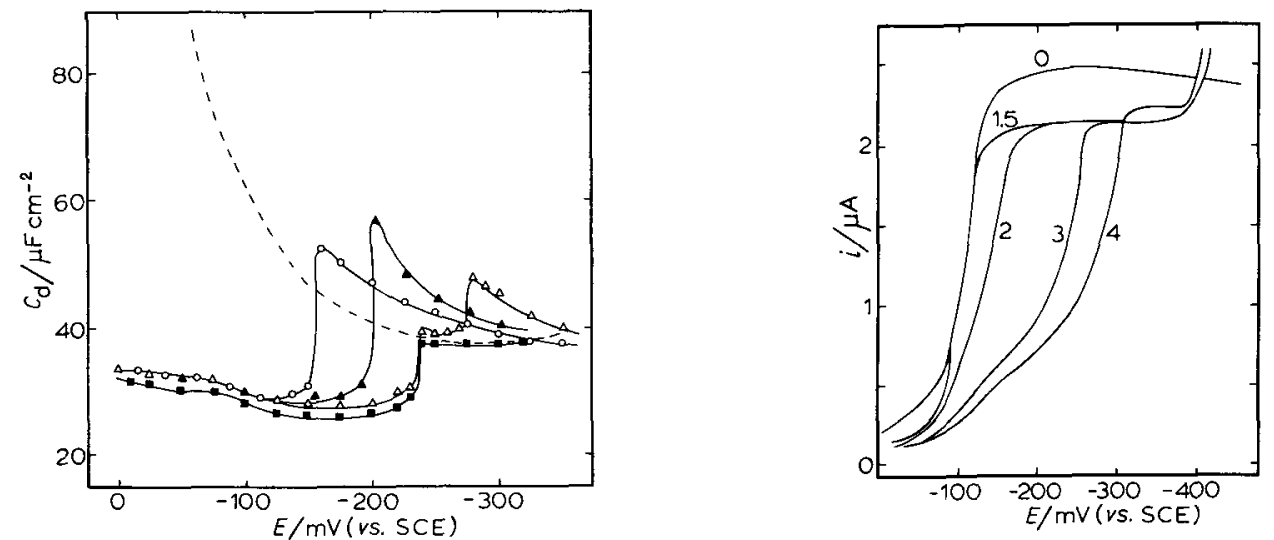

Fig. 3. Differential double-layer capacities of HMDE after $c a$. $60 \mathrm{~s}$ equilibration in $1 \mathrm{M} \mathrm{KCl}$ soln. containing $\mathrm{Pb}(\mathrm{II})$ at concns. : (--) $0,(\mathrm{O}) 1,(\mathbf{\Delta}) 1.5,(\triangle) 2,(\boldsymbol{D}) 3$ and $4 \mathrm{mM}$. Measuring frequency $1000 \mathrm{~Hz}$.

Fig. 4. D.c. polarograms of $\mathrm{Bi}(\mathrm{III})$ in $0.9 \mathrm{M} \mathrm{KCl}+0.1 \mathrm{M} \mathrm{HCl}$ at different $\mathrm{Pb}(\mathrm{II})$ concns., $0,1.5,2,3$ and $4 \mathrm{mM}$ (indicated by numbers). 
However, the jumps in capacities and $\Gamma_{\mathrm{Pb}(\mathrm{II})}$, observed at higher concentrations than $0.7 \mathrm{mM}$ or longer duration of the contact between electrode and solution, suggest that a reorientation takes place at higher coverages, which enables the adsorption of much more $\mathrm{Pb}(\mathrm{II})$ in the form of $\mathrm{PbCl}_{y}^{2-y}$. Since this coincides with the capacity drop to rather low values, it seems realistic to assume that a dense layer is formed with a net charge equal to zero; in other words, a layer of $\mathrm{PbCl}_{2}$. It should be stressed that the differences observed at the DME and the HMDE can be explained only on the assumption that the reorientation takes place after a certain level of $\Gamma_{\mathrm{Pb} \text { (I) }}$ has been reached.

(iv) Polarography of $\mathrm{Bi}(I I I)$ in the presence of $\mathrm{Pb}(I I)$

The polarographic reduction wave of $\mathrm{Bi}(\mathrm{III})$ in chloride solution is situated between -60 and $-130 \mathrm{mV} v$ s. SCE, i.e. in the region where the double-layer capacity is lowered in the presence of lead ions.

Figure 4 shows polarograms of $\mathrm{Bi}(\mathrm{III})$ in $0.9 \mathrm{M} \mathrm{KCl}+0.1 \mathrm{M} \mathrm{HCl}$ at different $\mathrm{Pb}$ (II) concentrations. The drop time of the DME was equal to that used in the capacity measurements.

In the absence of lead the bismuth wave exhibits a slight maximum. The wave is preceded by a small wave due to dissolved mercury, as generally accepted, in the form of $\mathrm{HgCl}_{4}^{2-}$. On addition of $1 \mathrm{mM} \mathrm{Pb}(\mathrm{II})$ the maximum disappears, but for the rest the polarogram remains the same. This polarogram is not shown in Fig. 4 for the sake of clarity. With $1.5 \mathrm{mM} \mathrm{Pb}(\mathrm{II})$ the bismuth wave is still unaffected, but the wave due to $\mathrm{Hg}(\mathrm{II})$ is clearly suppressed. This is in accordance with Fig. 1 where the capacity depression is found in the potential region 0 to $-70 \mathrm{mV} v$ s. SCE, just before the onset of the bismuth wave. With further increase of the lead concentration the bismuth wave becomes distorted: the current is significantly lowered but at a certain potential it rises rather steeply to the original limiting current. The potentials of these inclinations agree quite well with the potentials where the jumps in capacity occur at the various concentrations.

It can be concluded that the reduction of $\mathrm{Bi}(\mathrm{III})$ is inhibited as soon as the capacity potential curve indicates the occurrence of the dense layer of $\mathrm{PbCl}_{2}$, as was inferred above. We intend to present in a subsequent paper a more detailed study of this inhibition process.

\section{CONCLUSION}

In the foregoing we have already compared our results with the chronocoulometric results of Barclay and Anson pertaining to $0.7 \mathrm{mM} \mathrm{Pb}(\mathrm{II})$ in $1 M$ chloride solution. They found a linear relationship between $\Gamma_{\mathrm{Pb}(\mathrm{II})}$ and $\Gamma_{\mathrm{Cl}^{-}}$, the latter taken from data pertaining to $1 \mathrm{M} \mathrm{KCl}$ in the absence of $\mathrm{Pb}(\mathrm{II})$. They consider this behaviour to support the following mechanism

$$
\mathrm{Cl}_{\text {ads }}^{-}+\mathrm{PbCl}_{3}^{-} \rightarrow \mathrm{PbCl}_{4}^{2-} \text { ads }
$$

The values of $\Gamma_{\mathrm{Pb}(I I)}$ at $0.7 \mathrm{~m} M$ concentration are relatively low, so that saturation coverage will not be reached.

Another comparison is possible with the work of Gross and Murray ${ }^{10}$, who studied the adsorption of $\mathrm{Pb}(\mathrm{II})$ from $1 M$ bromide and iodide solutions. They find 
$\Gamma_{\mathrm{Pb}(\mathrm{II})}$ values of 8-9 $9 \times 10^{-10} \mathrm{~mol} \mathrm{~cm}^{-2}$ at fairly low $\mathrm{Pb}$ (II)-concentrations $(0.2-0.8 \mathrm{~m} M$ in bromide and $0.2-0.4 \mathrm{mM}$ in iodide), i.e. of the same order of magnitude as we find as "saturation levels" in chloride. On the basis of geometrical calculations, they conclude that this corresponds to the formation of a monolayer either of $\mathrm{Pb}-\mathrm{X}-\mathrm{Pb}-\mathrm{X}-$ chains parallel to the surface or of $\mathrm{X}-\mathrm{Pb} \mathrm{X}$ molecules perpendicular to the surface. The former model seems less probable since it would involve a positive net charge adsorbed at a positively charged electrode.

Our results in $1 M$ chloride with higher $\mathrm{Pb}$ (II) concentrations seem to indicate a quite new phenomenon, viz. that the adsorption behaviour as described by Barclay and Anson changes into the adsorption behaviour proposed by Gross and Murray as soon as the coverage by $\mathrm{Pb}(\mathrm{II})$ approaches a certain level.

\section{ACKNOWLEDGEMENT}

This investigation was supported in part by the Netherlands Foundation for Chemical Research (S.O.N.) with financial aid from the Netherlands Organisation for the Advancement of Pure Research (Z.W.O.).

\section{SUMMARY}

It is shown that when lead ions are adsorbed at the mercury- $1 \mathrm{M} \mathrm{KCl}$ solution interface the interface structure changes abruptly at certain potentials at higher $\mathrm{Pb}(\mathrm{II})$ concentrations. This is demonstrated by means of double-layer capacity measurements, chronocoulometric experiments and preliminarily by the inhibition phenomena in the d.c. polarogram of $\mathrm{Bi}(\mathrm{III})$.

\section{REFERENCES}

1 R. Parsons and A. Stockton, J. Electroanal. Chem., 25 (1970) App. 10.

2 P. Delahay and G. Susbielles, J. Phys. Chem., 70 (1966) 647.

3 M. Sluyters-Rehbach and J. H. Sluyters in A. J. Bard (Ed.), Electroanalytical Chemistry, Vol. IV, Marcel Dekker, New York, 1970.

4 F. C. Anson, Anal. Chem., 38 (1966) 54.

5 J. H. Christie, R. A. Osteryoung and F. C. Anson, J. Electroanal. Chem., 13 (1967) 236.

6 B. Timmer, M. Sluyters-Rehbach and J. H. Sluyters, J. Electroanal. Chem., 18 (1968) 93.

7 M. Caselli and P. Papoff, J. Electroanal. Chem., 23 (1969) 41.

8 D. J. Barclay and F. C. Anson, J. Electroanal. Chem., 28 (1970) 71.

9 B. Timmer, M. Sluyters-Rehbach and J. H. Sluyters, J. Electroanal. Chem., 15 (1967) $343 ; 19$ (1968) 73.

10 J. Gross and R. W. Murray, Anal. Chem., 38 (1966) 392, 405.

11 M. Sluyters-Rehbach and J. H. Sluyters, Rec. Trav. Chim., 82 (1963) 535.

12 G. Lauer and R. A. Osteryoung, Anal. Chem., 41 (1969) 1882.

J. Electroanal. Chem., 38 (1972) 